\title{
Rules regarding Marijuana and Its Use in Personal Residences: Findings from Marijuana Users and Nonusers Recruited through Social Media
}

\author{
Carla J. Berg, ${ }^{1}$ David B. Buller, ${ }^{2}$ Gillian L. Schauer, ${ }^{1}$ Michael Windle, ${ }^{1}$ \\ Erin Stratton, ${ }^{3}$ and Michelle C. Kegler ${ }^{1}$ \\ ${ }^{1}$ Department of Behavioral Sciences and Health Education, Emory University School of Public Health, \\ 1518 Clifton Road NE, Atlanta, GA 30322, USA \\ ${ }^{2}$ Klein Buendel, Inc., 1667 Cole Boulevard, Suite 225, Golden, CO 80401, USA \\ ${ }^{3}$ Immunization Services Division, National Center for Immunization and Respiratory Diseases, \\ Centers for Disease Control and Prevention, 1600 Clifton Road NE, Atlanta, GA 30329, USA \\ Correspondence should be addressed to Carla J. Berg; cjberg@emory.edu
}

Received 27 April 2015; Accepted 1 October 2015

Academic Editor: Chit Ming Wong

Copyright ( 2015 Carla J. Berg et al. This is an open access article distributed under the Creative Commons Attribution License, which permits unrestricted use, distribution, and reproduction in any medium, provided the original work is properly cited.

\begin{abstract}
Recent changes in policy and social norms related to marijuana use have increased its use and concern about how/where marijuana should be used. We aimed to characterize rules regarding marijuana and its use in homes. We recruited 1,567 US adults aged 1834 years through Facebook advertisements to complete an online survey assessing marijuana use, social factors, perceptions of marijuana, and rules regarding marijuana and its use in the home, targeting tobacco and marijuana users to ensure the relevance of this topic. Overall, 648 (41.6\%) were current marijuana users; $46.0 \%$ of participants reported that "marijuana of any type is not allowed in their home or on their property." Of those allowing marijuana on their property, $6.4 \%$ prohibited use of marijuana in their home. Of the remainder, $29.2 \%$ prohibited smoking marijuana, and $11.0 \%$ prohibited vaping, eating, or drinking marijuana. Correlates of more restrictive rules included younger age, being female, having <Bachelor's degree, not having parents or people living with them who use marijuana, perceiving use to be less socially acceptable and more harmful, and being a nonuser $(p$ 's $<.05)$. Attitudes and subjective norms regarding marijuana are correlates of allowing marijuana in residential settings. Future work should examine areas of risk regarding household marijuana rules.
\end{abstract}

\section{Introduction}

Marijuana is the most commonly used illicit drug in the US, particularly among young adults, with marijuana use prevalence increasing in recent years [1]. Chronic marijuana use is associated with cognitive impairment and addiction [2]. While marijuana can be used in various forms (e.g., vaporized and edible), the most common mode of use is smoking [3], which is implicated in long-term effects on lung function [4-6], chronic bronchitis and respiratory irritation $[2,4]$, and impaired immunological competence of respiratory systems [7].

Marijuana smoke includes nitric oxide, nitrogen oxide, hydrogen cyanide, and aromatic amine (which is responsible for the mutagenic and carcinogenic activity of cigarette condensates) and includes more chemicals than tobacco smoke [8]. In addition, risk factors of adolescent marijuana use include peer influence, home environment, and parental monitoring [9]. Thus, marijuana use in the home may impact health of nonusers and increase the likelihood of youth initiation.

Recent efforts regarding legalization and decriminalization of marijuana use in the US [10] restricts use to personal residential environments. Thus, we must understand how marijuana use is being voluntarily regulated in these settings; moreover, it is critical to understand correlates of having fewer restrictions on marijuana use in these settings to potentially inform interventions aimed at increasing certain restrictions. The Theory of Planned Behavior (TPB) [11], with its focus on the impact of attitudes, subjective norms, and 
perceived behavioral control on behavior, has been applied to adopting home restrictions for cigarette smoking and thus may be an appropriate framework for this issue. Notably, research has shown that attitudes about marijuana use and expectations of family members and close friends (i.e., subjective norms) are influential in predicting the adoption of smoke-free rules in residential settings $[12,13]$.

Given the importance of this emerging and complex public health issue, our research aims were to (1) characterize rules regarding marijuana and its use in households among young adult population recruited via an online social networking site and (2) document correlates of having less restrictive rules including sociodemographic factors, personal marijuana use, social factors, and perceptions of marijuana risk.

\section{Methods}

2.1. Procedures. The Emory University Institutional Review Board approved this study, IRB\# 00073636. We recruited participants aged 18-34 years via advertisements on Facebook, a social networking website, targeting tobacco and marijuana users and nonusers. Recruitment occurred over a three-week period in August 2014. We advertised to Facebook users who "liked" certain tobacco- or marijuana-related pages (e.g., major cigarette brands and magazines focusing on marijuana) or had identified related interests (e.g., "legalize marijuana"). Advertisements included images of tobacco products, marijuana-related images, and other benign images intended to recruit nonusers. Our recruitment was modeled after other published research methods [14].

2.2. Participants. Individuals who clicked on the advertisement were directed to a page describing the survey and the consent statement. Consenting individuals were screened for eligibility (i.e., age); those eligible were forwarded to the online survey, administered via http://www.surveygizmo .com/. To limit duplicate responses, one response per IP address was permitted. The survey took approximately 30 minutes to complete. Participants were compensated $\$ 5$.

Of the 4510 individuals who started the survey, 2251 did not complete the entire survey $(52.6 \%$ of whom did not move past the information and consent); 699 were disqualified, including 482 who were outside the age range, 77 who declined consent, and 140 who provided invalid responses. Thus, 1,567 had complete and valid responses. In our sample, 648 (41.6\%) were current marijuana users. The average number of days of use in the past 30 days was 17.86 $(\mathrm{SD}=11.29$; not shown in Table 1$)$. This high prevalence of marijuana use in this sample was intentional, per our recruitment approach targeting tobacco and marijuana users. We intended to ensure that the phenomenon of interest was relevant to the sample, particularly given that the vast majority of the US population does not face issues related to marijuana use in their home [1]. Marijuana users implicitly make decisions about use in the home, and tobacco users are more likely to affiliate with marijuana users [15], suggesting that they may also face decisions about marijuana use in their home. This sample allowed us to explore this phenomenon within a sample where this topic was relevant, including both marijuana users and marijuana nonusers.

2.3. Measures. The survey assessed standard sociodemographic factors and health-related factors; health-related factors included in the current analyses are detailed below.

2.3.1. Marijuana Use. Participants were asked, "In the past 30 days, on how many days did you use marijuana (pot, weed, hashish, hash oil)?” [1]. Those using marijuana in the past 30 days were considered current users.

2.3.2. Social Influence. Participants were asked if any parental figures, anyone living in their home, or their significant other uses marijuana and, out of his/her five closest friends, the number who use marijuana [15].

2.3.3. Perceptions of Marijuana. Participants were asked to rate on a scale of $1=$ "not at all" to $7=$ "extremely" the extent to which they perceived marijuana to be socially acceptable among peers, harmful to health, addictive, and harmful to those exposed to its byproducts. These measures were adapted from prior research [15].

2.3.4. Household Marijuana Rules (HMR). Participants were asked about rules about marijuana use in their current household. They indicated whether the statements listed in Table 2 were "never true" for them, "sometimes true," "always true," or "does not apply." To quantify the relative restrictions within the sample, an aggregate score of the household marijuana rules (HMR) index was derived by assigning a score of 0 for "never true," 1 for "sometimes true," and 2 for "always true" or "does not apply." "Does not apply" scored 2 because participants reporting this response were not allowing certain behaviors in those contexts by default. In addition, items skipped because of inclusive or restrictive rules leading to a skip pattern were treated as 2's as well. As such, higher scores reflect more restrictions on marijuana in participants' households.

2.4. Data Analysis. Participant characteristics were summarized using descriptive statistics. Bivariate analyses were conducted comparing marijuana users versus nonusers and associations with HMR index scores. A multivariable regression model was then developed to identify correlates of HMR, employing backwards stepwise entry at $p<.10$. SPSS 22.0 was used for all data analyses. Statistical significance was set at $\alpha=.05$ for all tests.

\section{Results}

Table 1 presents data indicating that marijuana users versus nonusers were younger $(\mathrm{M}=24.49 \pm 5.09$ versus $\mathrm{M}=$ $25.67 \pm 5.03, p<.001$ ), were less educated ( $>\mathrm{HS}=63.0 \%$ versus $70.7 \%, p<.001)$, and were more likely to be married or living with a partner $(62.3 \%$ versus $54.5 \%, p=.001)$. In terms of social factors, they were more likely to be living 
TABLE 1: Participant characteristics and bivariate analyses demonstrating associations with HMR index scores.

\begin{tabular}{|c|c|c|c|}
\hline Variable & $\begin{array}{c}\text { Total } \\
N=1567 \\
N(\%) \text { or } \\
\mathrm{M}(\mathrm{SD})\end{array}$ & $\begin{array}{l}\text { Association with HMR } \\
\text { M (SD) } \\
\text { or } r\end{array}$ & $p$ value \\
\hline \multicolumn{4}{|l|}{ Sociodemographics } \\
\hline Age (SD) & $25.18(5.09)$ & -0.07 & .006 \\
\hline Gender (\%) & & & .029 \\
\hline Male & $766(49.1)$ & $26.94(7.41)$ & \\
\hline Female & $776(49.7)$ & $27.73(6.89)$ & \\
\hline Race (\%) & & & .151 \\
\hline White & $1356(86.9)$ & $27.22(7.22)$ & \\
\hline Other & $204(13.1)$ & $28.00(6.72)$ & \\
\hline Ethnicity (\%) & & & .785 \\
\hline Hispanic/Latino & $201(13.0)$ & $27.44(7.23)$ & \\
\hline Other & $1341(87.0)$ & $27.29(7.17)$ & \\
\hline Education (\%) & & & .083 \\
\hline$\leq$ High school & $508(32.6)$ & $27.89(6.99)$ & \\
\hline Some college & $795(51.0)$ & $26.99(7.34)$ & \\
\hline$\geq$ Bachelor's degree & $257(16.5)$ & $27.24(6.90)$ & \\
\hline Parental education (\%) & & & .002 \\
\hline$\leq$ High school & $437(28.0)$ & $28.34(6.68)$ & \\
\hline Some college & $489(31.4)$ & $27.04(7.14)$ & \\
\hline$\geq$ Bachelor's degree & $633(40.6)$ & $26.83(7.44)$ & \\
\hline Employment status (\%) & & & .393 \\
\hline Employed full or part time & $788(50.5)$ & $27.11(7.34)$ & \\
\hline Full or part time student & $334(21.4)$ & $27.36(6.78)$ & \\
\hline Unemployed/other & $438(28.1)$ & $27.69(7.11)$ & \\
\hline Sexual orientation (\%) & & & .035 \\
\hline Heterosexual & $1222(78.6)$ & $27.53(7.00)$ & \\
\hline Other & $333(21.4)$ & $26.59(7.68)$ & \\
\hline Community type (\%) & & & .133 \\
\hline Rural & $400(25.6)$ & $27.68(6.82)$ & \\
\hline Urban & $491(31.5)$ & $26.80(7.49)$ & \\
\hline Suburban & $669(42.9)$ & $27.49(7.10)$ & \\
\hline \multicolumn{4}{|l|}{ Social factors } \\
\hline Relationship status (\%) & & & .748 \\
\hline Married/living with partner & $659(42.3)$ & $27.27(7.17)$ & \\
\hline Other & $900(57.7)$ & $27.83(7.15)$ & \\
\hline Living situation (\%) & & & .001 \\
\hline Live alone & $133(8.5)$ & $27.29(6.68)$ & \\
\hline Live with spouse/partner & $600(38.5)$ & $27.14(7.16)$ & \\
\hline Live with friends/relatives & $364(23.3)$ & $26.13(8.07)$ & \\
\hline Live with parents & $347(22.2)$ & $28.47(6.47)$ & \\
\hline Live on campus & $81(5.2)$ & $28.64(6.31)$ & \\
\hline Other & $35(2.2)$ & $28.69(4.99)$ & \\
\hline
\end{tabular}


TABle 1: Continued.

\begin{tabular}{|c|c|c|c|}
\hline Variable & $\begin{array}{c}\text { Total } \\
N=1567 \\
N(\%) \text { or } \\
\mathrm{M}(\mathrm{SD})\end{array}$ & $\begin{array}{c}\text { Association with HMR } \\
\text { M (SD) } \\
\text { or } r\end{array}$ & $p$ value \\
\hline Have children (\%) & & & .426 \\
\hline No & $1112(71.3)$ & $27.23(7.22)$ & \\
\hline Yes & $448(28.7)$ & $27.55(7.02)$ & \\
\hline Parental figure uses marijuana & & & $<.001$ \\
\hline No & $1290(82.7)$ & $28.02(6.64)$ & \\
\hline Yes & $270(17.3)$ & $23.99(8.51)$ & \\
\hline People who live with you use marijuana & & & $<.001$ \\
\hline No & $1121(71.9)$ & $28.82(6.10)$ & \\
\hline Yes & $270(17.3)$ & $23.51(8.20)$ & \\
\hline Partner uses marijuana & & & $<.001$ \\
\hline No partner/no use & $1265(81.1)$ & $28.15(6.52)$ & \\
\hline Yes & $294(18.9)$ & $23.76(8.60)$ & \\
\hline Number of 5 closest friends using marijuana & $2.43(1.90)$ & -0.34 & $<.001$ \\
\hline Social acceptability of marijuana use & $5.08(2.15)$ & -0.28 & $<.001$ \\
\hline \multicolumn{4}{|l|}{ Perceptions of harm and use } \\
\hline Harm to health of marijuana use & $2.99(2.08)$ & 0.22 & $<.001$ \\
\hline Harm to health of marijuana byproducts & $3.14(2.16)$ & 0.22 & $<.001$ \\
\hline Addictiveness of marijuana & $3.04(2.17)$ & 0.10 & $<.001$ \\
\hline
\end{tabular}

with friends/relatives (26.9\% versus $20.9 \%$ ), have parental figures who use marijuana $(29.9 \%$ versus $8.3 \%, p<.001)$, have people who live with them use marijuana (48.0\% versus $14.0 \%, p<.001)$, and have a partner who uses marijuana (36.1\% versus $6.5 \%, p<.001)$ but less likely to have children (23.9\% versus $32.0 \%, p<.001)$. Users also had more friends who used marijuana $(M=3.85 \pm 1.36$ versus $M=1.42 \pm 1.55$, $p<.001)$. In terms of other attitudes about marijuana use, marijuana users versus nonusers perceived marijuana to be more socially acceptable $(\mathrm{M}=6.11 \pm 1.48$ versus $\mathrm{M}=$ $4.34 \pm 2.26, p<.001)$, less harmful $(\mathrm{M}=2.18 \pm 1.49$ versus $\mathrm{M}=3.57 \pm 2.42, p<.001)$, and less addictive $(\mathrm{M}=2.54 \pm 1.79$ versus $M=3.40 \pm 2.34, p<.001)$ and perceived exposure to marijuana byproducts to be less harmful $(\mathrm{M}=2.30 \pm 1.66$ versus $\mathrm{M}=3.75 \pm 2.28, p<.001)$.

Overall, $46.0 \%$ (24.8\% of users; $61.1 \%$ of nonusers) reported that marijuana of any type is not allowed on their property (Table 2). In addition to those not allowing it on the property, $6.4 \%$ (5.5\% of users, $7.7 \%$ of nonusers) prohibited marijuana use on their property. Of those that allowed some level of marijuana use on their property, 29.2\% prohibited marijuana smoking in their home, $11.0 \%$ prohibited vaping, eating, or drinking marijuana, and $8.4 \%$ prohibited its use in outdoor areas. Only $1.9 \%$ of all participants $(N=30 / 1560)$ allowed marijuana use in the presence of children, with little variability depending on how it was used (e.g., smoked or vaped).

Marijuana users versus nonusers had higher HMR index scores $(M=24.54 \pm 8.15$ versus $M=29.29 \pm 5.59$, resp., $p<.001)$. Other factors associated with higher HMR scores (Table 1$)$ included younger age $(p=.006)$; being female $(p=.029)$; lower parental educational background $(p=$ $.002)$; being heterosexual $(p=.035)$; living with parents or on campus versus other situations ( $p=.001)$; not having parents, others in the home, or a partner who uses marijuana ( $p$ 's < .001); having fewer friends who use $(p<.001)$; perceiving marijuana use to be less socially acceptable, more harmful, and more addictive ( $p$ 's $<.001)$; and perceiving marijuana byproducts to be more harmful ( $p$ 's $<.001)$.

Prior to constructing the multivariable model predicting HMR index scores, we explored collinearity among the predictors of interest. We found that number of friends who smoke was collinear with perceived social acceptability and personal use and that perceptions of harm of marijuana byproducts was collinear with perceived harm of marijuana. Thus, we excluded these two variables and entered all other factors associated with HMR index scores at the $p<.10$. Predictors of higher HMR index scores included younger age $($ Beta $=-0.16, \mathrm{CI}-0.22,-0.09)$, being female (Beta $=$ -0.69 , CI $-1.31,-0.07)$, having a Bachelor's degree or higher education (Beta $=-0.57, \mathrm{CI}-1.06,-0.08)$, not having a parent (Beta $=-2.00, \mathrm{CI}-2.88,-1.11)$ or people living in their home who used/uses marijuana (Beta $=-3.40$, CI $-4.18,-2.63$ ), perceiving marijuana use to be less socially acceptable (Beta = -0.43 , CI $-0.60,-0.26$ ) and more harmful (Beta $=0.31, \mathrm{CI}$ $0.14,0.47)$, and less likelihood of being a marijuana user $\left(\right.$ Beta $=-2.16, \mathrm{CI}-2.94,-1.39$; adjusted $R^{2}=0.206$ ).

\section{Discussion}

This study is the first to characterize voluntary restrictions on marijuana in home environments. As expected, the newly 


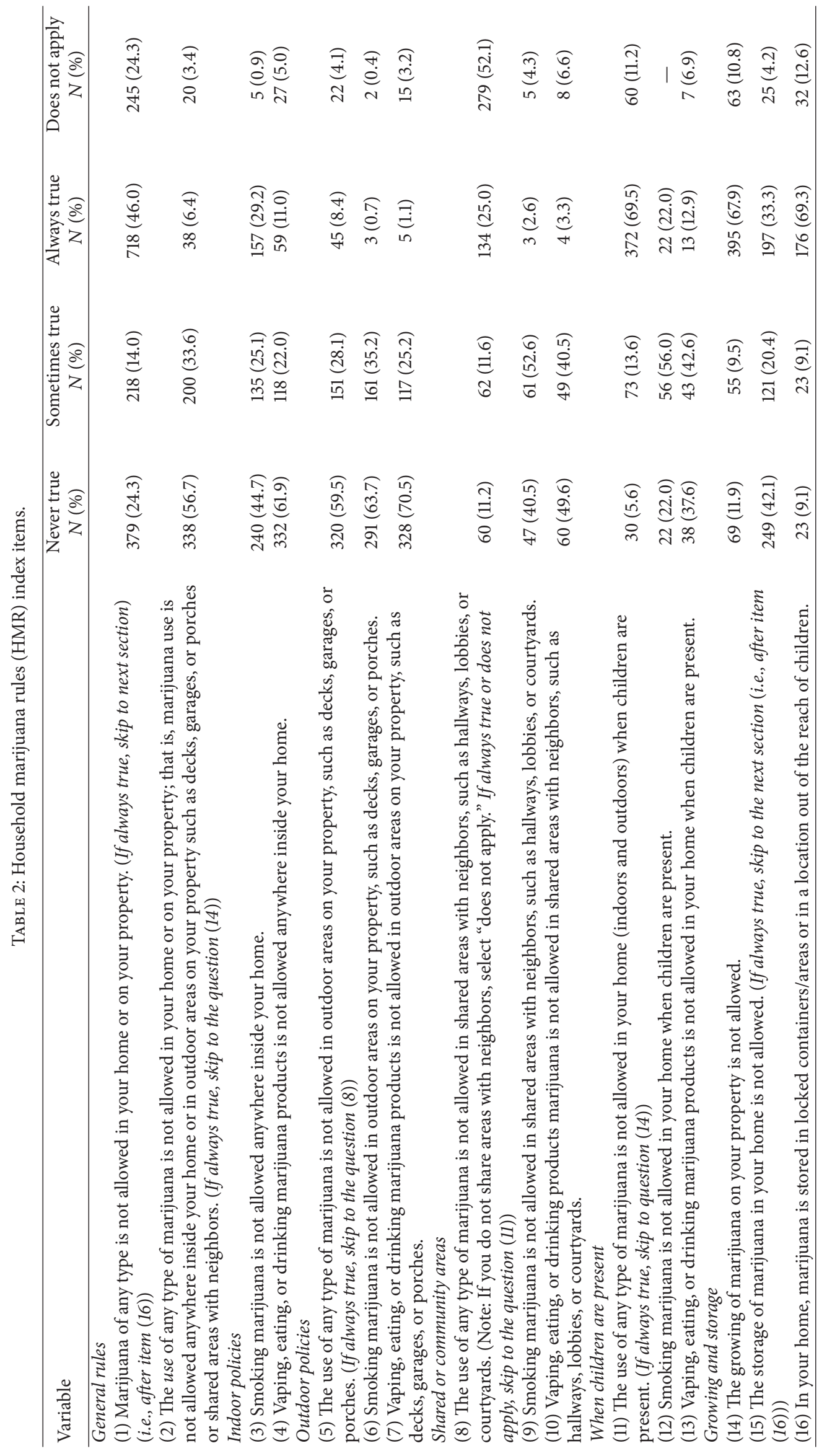


developed index correlated with theoretical factors per the TPB [11], such as attitudes toward marijuana (e.g., perceptions of harm and addictiveness) and social factors (e.g., important others' marijuana use); these findings are in line with those derived from the home smoking restrictions literature [12, 13]. There was an association between more restrictions and sociodemographics including younger age, gender, and education, which warrant further examination.

In this sample of young adults, nearly half (46.0\%) prohibited marijuana on their property, the majority of whom were nonusers. Additionally, a quarter of users prohibited marijuana on their property, implying use outside of the home. There were also some differences in the restriction of smoked marijuana versus noncombustible marijuana in the home, which might suggest that some young adults feel that covert (i.e., noncombustible) use is more acceptable. In addition, a small percentage had rules about use in outdoor areas, which might impact neighbors, be observable by individuals off the property (i.e., on sidewalks), and be subject to legal restrictions, particularly in multiunit housing. Finally, marijuana use in the presence of children was rarely allowed. This is favorable, as substance use by parents and other adults may normalize use and encourage youth initiation.

These findings have implications for research and practice. This index might inform research regarding risks related to marijuana in residential environments, which is critical in a rapidly evolving context of marijuana regulations [10] and the need to intervene to circumvent the potential harms of marijuana secondhand smoke [8] and the impact on youth initiation [9]. Future research should also qualitatively examine how rules are voluntarily adopted and communicated within one's social system and identify other possible rules used in these and other settings. It would also be useful to determine how well individuals understand legal restrictions on use in residential location and whether the rules as they express them are consistent with these laws.

Furthermore, more research is needed to inform the appropriate public health outcome, particularly given the limited research regarding the impact of secondhand marijuana smoke exposure. Specifically, should the objective be a full household ban? If so, where should use be allowed, since use in public is precluded by legalization policies and may have other public health consequences? Alternatively, is the objective to ban smoked forms of marijuana in the home or prevent use in the presence of youth? If so, should noncombustible marijuana use and/or proper storage be encouraged? Even in a time of uncertainty regarding desired outcomes, surveillance regarding how people approach household marijuana rules can inform future efforts to address marijuana use in the home.

\section{Limitations}

Limitations include limited generalizability given that the sample was focused on young adults and specifically targeted marijuana and tobacco users in order to ensure that the phenomenon of interest was relevant to the sample obtained. Also, this sample was mainly drawn from North America and thus is unlikely to represent the attitudes and values of people worldwide. We also had a relatively low response rate, which is open to selection bias. Future research should examine these and other related phenomena among a more representative national sample. Specifically, research might explore other dimensions of how people regulate marijuana use in other settings (e.g., cars). Additionally, the online survey format does not allow us to explore the reasons why individuals might have reported "does not apply" for certain items. Finally, the cross-sectional nature of this study limits the ability to make causal attributions.

\section{Conclusions}

Attitudes about marijuana use and subjective norms related to use are important correlates of allowing marijuana and its use in residential settings. Marijuana users versus nonusers had fewer household marijuana rules. Moreover, use in the presence of children was rare. These findings have implications for future research aimed at objectively examining areas of risk regarding household marijuana rules and informing intervention efforts aimed at reducing exposure to marijuana byproducts and youth exposure to marijuana use.

\section{Ethical Approval}

The Emory University Institutional Review Board approved this study, IRB\# 00073636.

\section{Conflict of Interests}

The authors declare no conflict of interests.

\section{Acknowledgment}

This work was conducted at Emory University, Atlanta, GA 30322, USA. This research was supported by the National Cancer Institute (1K07CA139114-01A1; PI: Berg) and the Georgia Cancer Coalition (PI: Berg).

\section{References}

[1] Substance Abuse and Mental Health Services Administration (SAMHSA), Results from the 2012 National Survey on Drug Use and Health: Summary of National Findings, NSDUH Series H46, HHS Publication No. (SMA) 13-4795, Substance Abuse and Mental Health Services Administration, Rockville, Md, USA, 2013.

[2] N. D. Volkow, R. D. Baler, W. M. Compton, and S. R. B. Weiss, "Adverse health effects of marijuana use," The New England Journal of Medicine, vol. 370, no. 23, pp. 2219-2227, 2014.

[3] M. Joshi, A. Joshi, and T. Bartter, "Marijuana and lung diseases," Current Opinion in Pulmonary Medicine, vol. 20, no. 2, pp. 173179, 2014.

[4] W. Hall and L. Degenhardt, "Adverse health effects of nonmedical cannabis use," The Lancet, vol. 374, no. 9698, pp. 13831391, 2009.

[5] M. H. S. Lee and R. J. Hancox, "Effects of smoking cannabis on lung function," Expert Review of Respiratory Medicine, vol. 5, no. 4, pp. 537-547, 2011. 
[6] J. M. Tetrault, K. Crothers, B. A. Moore, R. Mehra, J. Concato, and D. A. Fiellin, "Effects of marijuana smoking on pulmonary function and respiratory complications: a systematic review," Archives of Internal Medicine, vol. 167, no. 3, pp. 221-228, 2007.

[7] D. P. Tashkin, G. C. Baldwin, T. Sarafian, S. Dubinett, and M. D. Roth, "Respiratory and immunologic consequences of marijuana smoking," Journal of Clinical Pharmacology, vol. 42, no. 11, supplement, pp. 71S-81S, 2002.

[8] D. Moir, W. S. Rickert, G. Levasseur et al., "A comparison of mainstream and sidestream marijuana and tobacco cigarette smoke produced under two machine smoking conditions," Chemical Research in Toxicology, vol. 21, no. 2, pp. 494-502, 2008.

[9] K. G. Hill, J. D. Hawkins, R. F. Catalano, R. D. Abbott, and J. Guo, "Family influences on the risk of daily smoking initiation," Journal of Adolescent Health, vol. 37, no. 3, pp. 202-210, 2005.

[10] R. Room, "Legalizing a market for cannabis for pleasure: Colorado, Washington, Uruguay and beyond," Addiction, vol. 109, no. 3, pp. 345-351, 2014.

[11] I. Ajzen, "The theory of planned behavior," Organizational Behavior and Human Decision Processes, vol. 50, no. 2, pp. 179211, 1991.

[12] R. Borland, H.-H. Yong, K. M. Cummings, A. Hyland, S. Anderson, and G. T. Fong, "Determinants and consequences of smoke-free homes: findings from the International Tobacco Control (ITC) Four Country Survey," Tobacco Control, vol. 15, supplement 3, pp. iii42-iii50, 2006.

[13] P. I. Clark, M. W. Schooley, B. Pierce, J. Schulman, A. M. Hartman, and C. L. Schmitt, "Impact of home smoking rules on smoking patterns among adolescents and young adults," Preventing Chronic Disease, vol. 3, no. 2, article A41, 2006.

[14] D. E. Ramo and J. J. Prochaska, "Broad reach and targeted recruitment using Facebook for an online survey of young adult substance use," Journal of medical Internet research, vol. 14, no. 1, article e28, 2012.

[15] C. J. Berg, E. Stratton, G. L. Schauer et al., "Perceived harm, addictiveness, and social acceptability of tobacco products and marijuana among young adults: marijuana, hookah, and electronic cigarettes win," Substance Use \& Misuse, vol. 50, no. 1, pp. 79-89, 2015. 


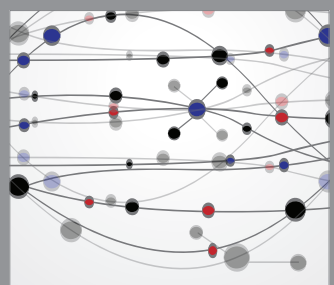

The Scientific World Journal
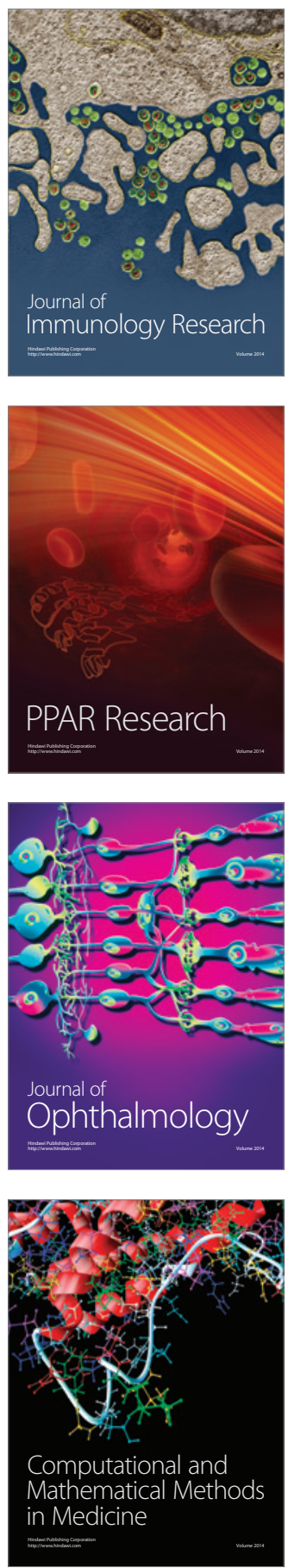

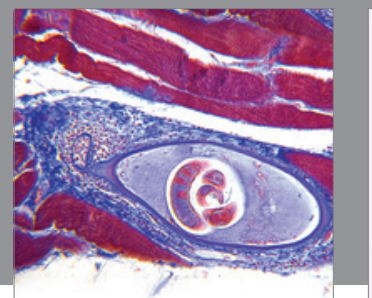

Gastroenterology

Research and Practice
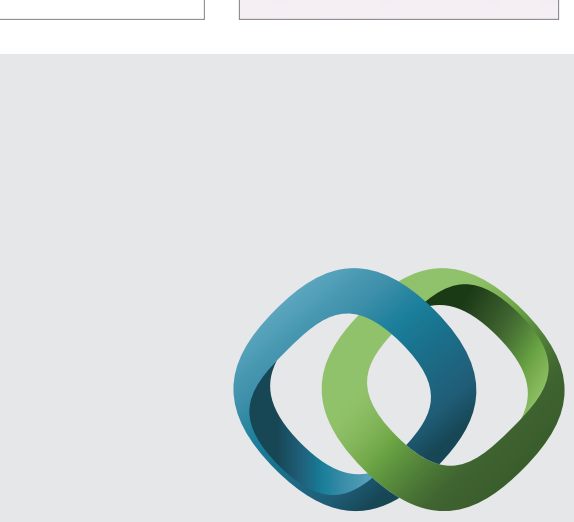

\section{Hindawi}

Submit your manuscripts at

http://www.hindawi.com
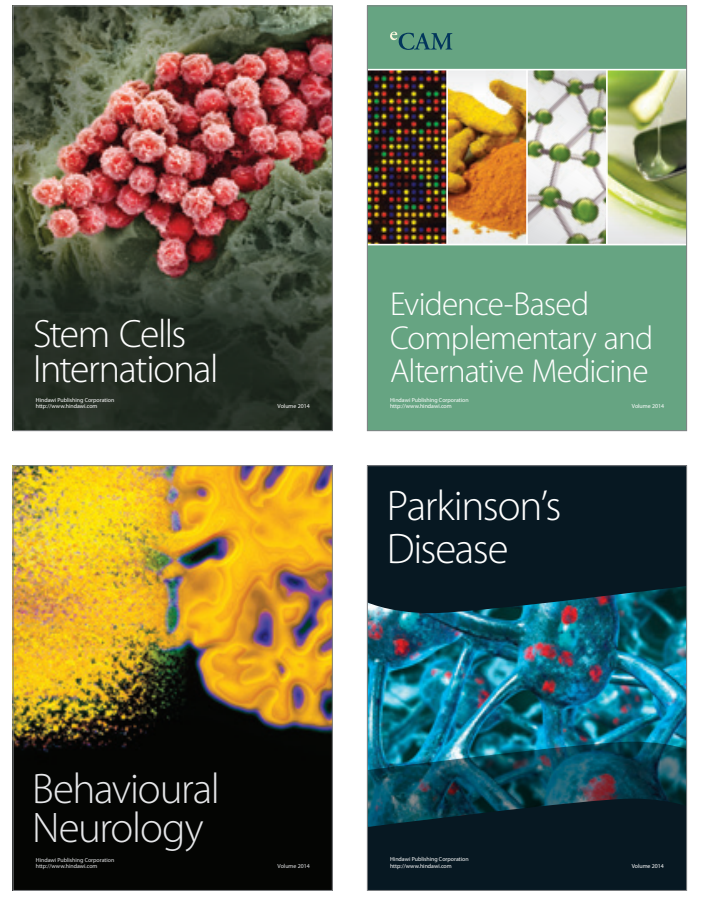
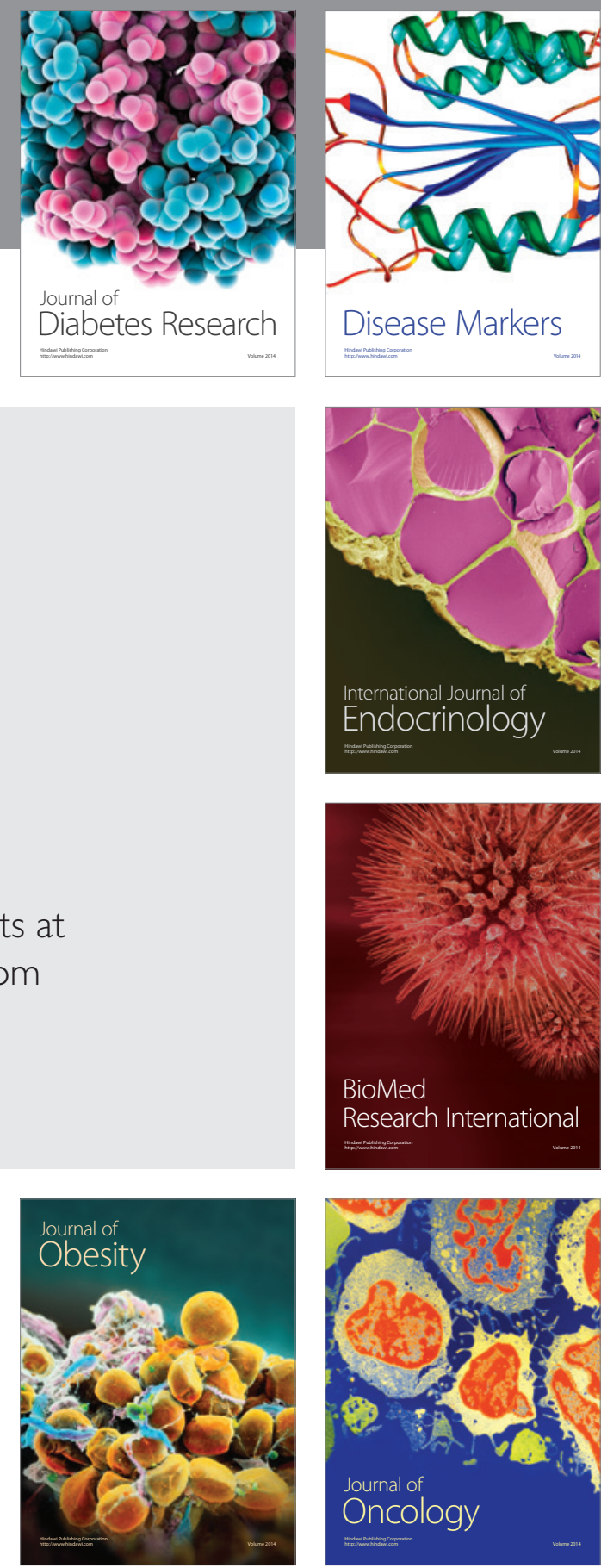

Disease Markers
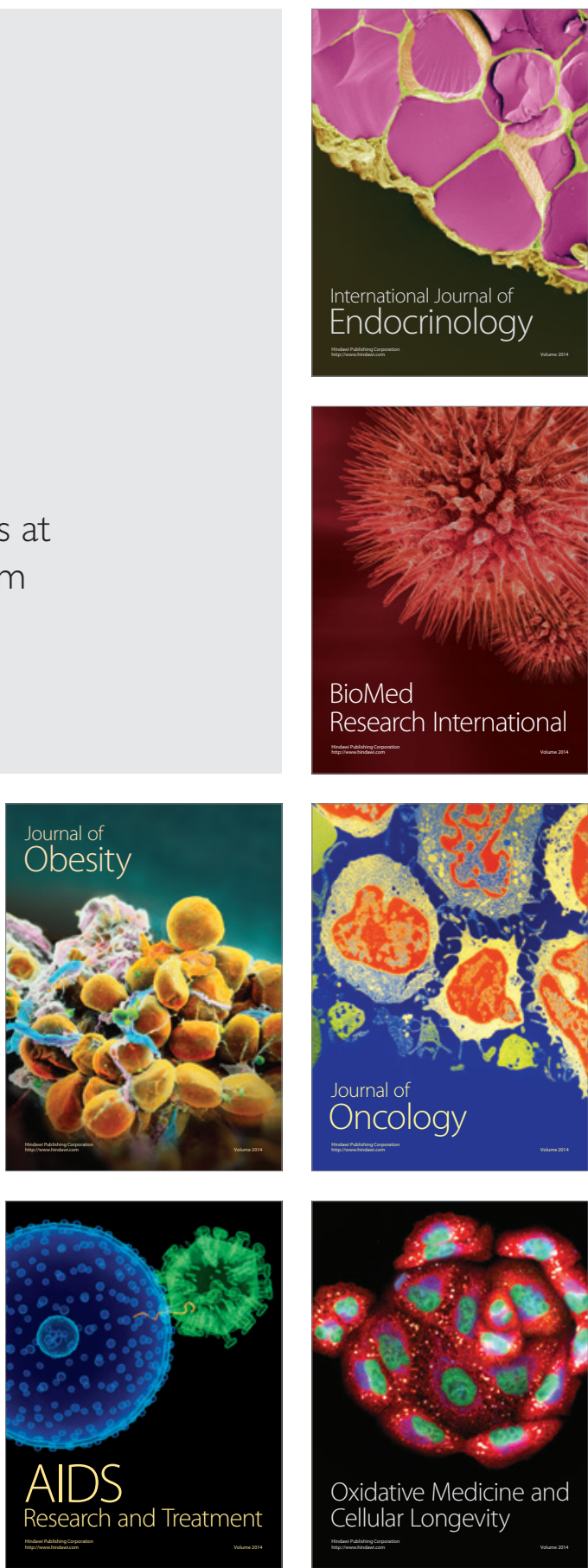